\title{
A Water-cooled Radiator Driven by Memory Alloy
}

\author{
Yang Liu \\ 9 students department building of North China Electric Power University (Baoding). Huadian Road \\ No. 689. Baoding City in Hebei,China \\ 835341518@qq.com
}

Keywords: Water-cooled electronic radiator, Ni-Ti memory alloy, Dual diameter pulley turbine, Cobweb model.

\begin{abstract}
The traditional electronic equipment cooling system uses electric to drive water pump, it will consume energy. The motor operating power is constant, resulting in a waste of power. After cutting off the power supply, water pumps stop working so that the heat inside the appliance can't be cleared. In this paper, use the recovery characteristics of shape memory alloy to create dual diameter pulley turbine, the two groups of alloy wires including heat coil and cold coil drive dual diameter pulley turbine rotating to form a pump system to replace the traditional water cooling system driven by an electric pump in order to save energy. Then the article analyses the system stability with Cobweb model. Realize the innovation of structure and principles. Enhance environmental protection of the water-cooled units.
\end{abstract}

\section{Traditional Way of Driving Water-cooled System}

Water coolingknown asliquid cooling, the efficiency of water-cooledis 20 times than air-cooled. In addition to the specific heat capacityand density ofliquidis much larger than gas,water cooling can makethe systemstructure more compact.Cooling systemneed to usea pumpto providepressure tocirculate waterinsystem, coolingfluidmake heat transferprocessbetweenthe wall of pipeandradiator. Traditionalwater-cooledelectronicradiator's water pumpimpelleris rotatedby electric motortodrivewaterflowingin the pipe. Electric drivewill consumesome energy. The use of electric-driven motor makes output power a constant, resulting in a waste of power. Aftercutting offthe power supply,water pumpsstop working, so thattheheatinside the appliancecan't bescattered, causing the lossof electricallife.As can be seen, there are manynon-environmental considerations in traditional water cooling system.

\section{Memory Alloy Driven Approach of Water Cooler}

Nickel-Titaniummemory alloy will form areversiblethermo-elasticmartensitic transform ation when cooled below a certain temperature. The recovery of shape can be achievedat high temperatures. Whenthe shape memoryalloyeffect occurs, it will result a greatforce so that we can usethe shape memoryeffectto transferheatinto mechanical energy. In 1977,Johnsonproposeddualdiameter pulley turbineengine [1]: the pulleyguid enitinol spiral coilthrough cold sink andhotwater tank, one coil is suspended ona dualdiameter pulley turbineto cause thestretcheffect; the other is suspended to cause compressioneffect.The heating coil's tensionis greater than thecoolingcoil's tension, so it willresultpoweroutputting.

As the Fig. 1 shows, with the use of memory alloy dualdiameter pulley turbine principle, the heat sink pulley 3 is provided in the collector device 5, the heat generated by the heating element 5-1 go through the first metal radiator 4 so that nitinol wire13 wounded on the hot groove pulley will produces tension by thermal expansion; cold groove pulley 10 is provided on slot 9 of the cooling liquid reservoir 8 , the nitinol wire wounded on a cold groove pulley will produce tension by cold contraction; the two sets of coils are set on the same differential double diameter pulley 1 . This time, the power done by the hot spiral coil's tension is greater than the power done by the tension of the cold spiral coil, making dualdiameter pulley rotates by the force difference between the hot helical coil and cold spiral coil, so as to drive the impeller 12 and the linkage 11 which connected to the 
pulley to rotate, so the pump device is formed. This pump system instead of the traditional electric water-cooled cooling system pumps, drive cold water through the second conduit 2-1 from the cold water storage tank, and out to the enclosed drive slot 14, and then flows go through the first conduit 2 to collector device, cold water absorb the heat in element area where the heat continue to heat up to form hot water, then flow through the heating zone by third conduit2-2 into the heat exchanger, radiator cooling fan 7 and metal heat exchanger 6 will make heat dissipation of water. The cooled water flows back to 8 to achieve the purpose of cooling the heating elements.

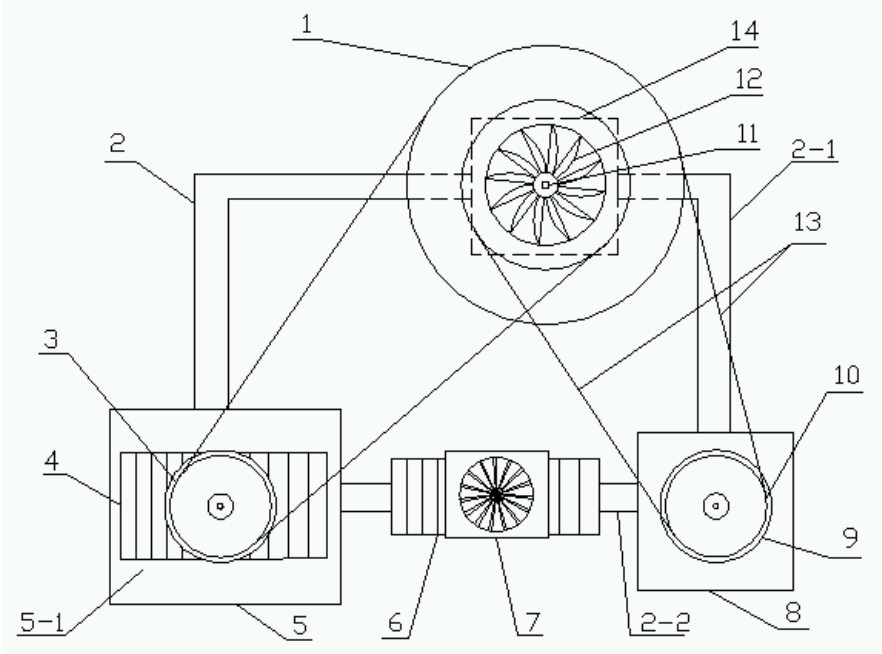

Fig. 1 Diagram of water cooling system driven by memory alloy

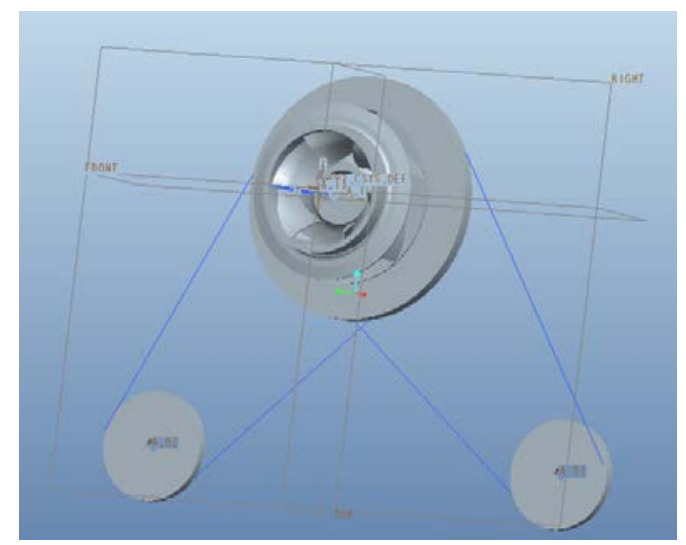

Fig. 2 3D model of memory alloy pump system

As can be seen, thiswork retains the traditionalwater coolercollectormodules, flow ducts, etc. Add the heats storagemodule andmemory alloymodules, to usememory alloyheat engine to replaceelectricmotorcoolingpumps. Memory alloy drivingthewater coolercan beadjusted with theinternaltemperature of the powerchangingsize. Afterthe heating elements cutting off power, theheatpump systemcan continue to work driven by disperseheat, which will help prolongthe life ofelectrical appliances, and enhance the cooling system's environmental protection.

\section{Theoretical Analysis of Stability with Cobweb Model}

The calculation formula for the efficiency of memory alloy engine is shown below [1]:

$$
\eta=\frac{\Delta T(0)}{T_{0}(0)}\left(\frac{\ln (1+\xi)}{\xi}\right) / \frac{T_{0}(\sigma)}{T_{0}(0)}+\frac{\bar{C}_{p} \Delta T_{0}}{\Delta Q(0)}
$$

According to the data of nickel-titanium alloy [1]: $\xi=0.10, \bar{C}_{p}=4 \mathrm{card} / \mathrm{mole}, T_{0}=100 \mathrm{~K}, \Delta Q$ $=100 \mathrm{card} / \mathrm{mole}, \Delta T_{0}=100 \mathrm{~K}, A_{f}=110 \mathrm{~K}, M_{f}=70 \mathrm{~K}$, obtained the efficiency of heat engines is $20 \%$. 
By using the knowledge of thermodynamics, we can know the memory alloy heat engine power calculation formula is:

$$
P=\Delta q_{Q} \eta=0.2 \Delta q_{Q}
$$

For example, use a typical computer water cooler to analyze the stability of this new type water cooler. According to the data [3], when the traditional computer water cooler's pump engine at 70 degrees (close to the electronic components of a stable operating temperature limit) and 21 degrees (water temperature) when operating, the speed is $2000 \mathrm{rpm}$, power is 0.217 watts. Heat transfer flow $\Delta q_{Q}$ is about $1.8 \mathrm{w}$.

The acting loss coefficient $\eta_{\text {loss }}$ (including hydraulic pipeline flow loss and the rotation of the impeller friction losses, etc.) is about 0.7 according to data [2]. We can calculate the power of memory alloy pump using Eq. 2.

$$
P=\Delta q_{Q} \eta \eta_{\text {loss }}=0.2 \times 0.7 \times 1.8=0.252 \mathrm{w}
$$

It can be seen that the maximum power is more than $0.217 \mathrm{w}$, so memory alloy pump performance can meet the needs of water cooling max limit.

Now, use Cobweb model to analyze the working stability. First, analyze the influence between the memory alloy pump and heat source.

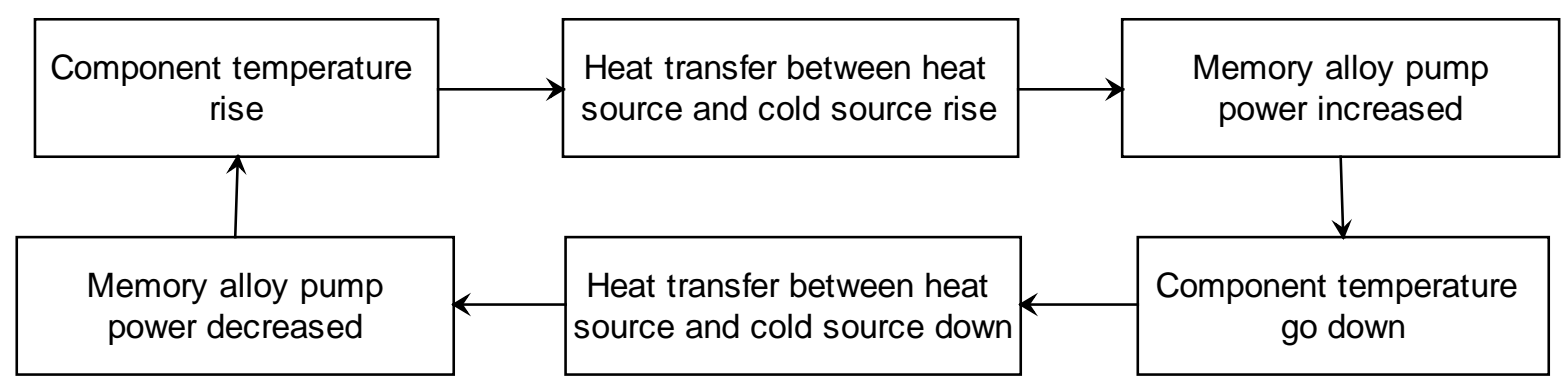

Fig. 3 Influence between the memory alloy pump and heat source

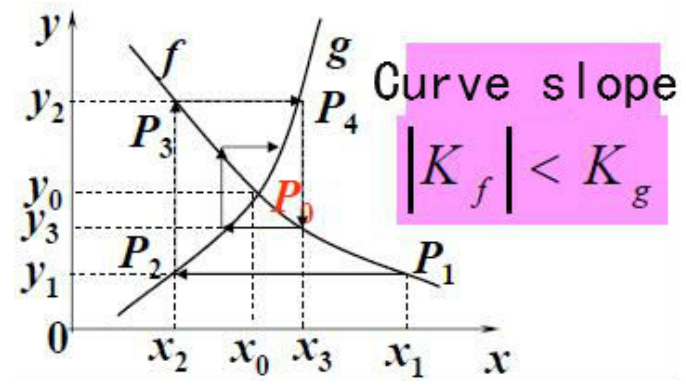

Fig. 4 Cobweb analysis

It can be seen that the power of the memory alloy and the element temperature (or heat) there is a negative feedback phenomenon, power and temperature in the upper and lower shock. Set $X_{k}$ to the power of the memory alloy pump at the $\mathrm{K}$ time period and $y_{k}$ to the temperature of the heating element for the period $\mathrm{K}$, then the following formula can be obtained:

$$
\left\{\begin{array}{l}
x_{k+1}=h\left(y_{k}\right) \Leftrightarrow y_{k}=g\left(x_{k+1}\right) \\
y_{k}=f\left(x_{k}\right)
\end{array}\right.
$$

Among them, the $\mathrm{h}$ function as an increase function represents the positive feedback on the increase in power of temperature increasing, its anti function $g$ is also an increase function ; the $f$ function as a reducing function represents the negative feedback on the temperature reducing of the power increasing. 
By $y_{k}=f\left(x_{k}\right) \quad x_{k+1}=h\left(y_{k}\right) \Leftrightarrow y_{k}=g\left(x_{k+1}\right)$, it can be pushed $x_{1} \rightarrow y_{1} \rightarrow x_{2} \rightarrow y_{2} \rightarrow \ldots$. When $\left|K_{f}\right|<K_{g}$, we can know $x_{k} \rightarrow x_{0}, y_{k} \rightarrow y_{0}$, that it is stable:

For the works of the cobweb model, with the function $\mathrm{f} \& \mathrm{~g}$ approximation for linear, mathematics to describe as:

$$
\left\{\begin{array}{l}
g\left(\lim x_{n+1}\right)>\lim y_{n}, g(0)=0 \Rightarrow K_{g}>\lim \frac{y_{n}}{x_{n+1}}=M \\
f(0)=\lim y_{n}, f\left(\lim x_{n}\right)=0 \Rightarrow\left|K_{f}\right|=\lim \frac{y_{n}}{x_{n}}=M
\end{array}\right.
$$

The meaning of $g\left(\lim x_{n+1}\right)>\lim y_{n}$ is that the actual power of the memory alloy when the heat source reaches the limit temperature is less than that of the memory alloy. So we can push $\left|K_{f}\right|<K_{g}$ which means the system can work in a stable condition.

\section{Summary}

Coolingof electronic equipmentis mainly divided intoair-cooledandwater-cooled,water coolingwith its highthermal efficiency,lownoisecharacteristics is morefavored. The traditionalwater coolingequipmentpumps has many non-environmental factors because ofelectric-drivenway. To solve the problem above, according tothe recoverycharacteristics ofmemory alloys, use shape memory alloysolidheat enginedrivingpumpinstead of the traditionalwater-cooledelectric motordrivenpump for the energy-saving purposes, which will help prolongthe life ofappliances, in line withthe sustainabledevelopment concept, enhance thecooling system's environmental protection, and achieve innovation.

\section{Reference}

[1] Mao Wenqin. Shape memory alloy engine of [D]. Hangzhou Dianzi University, 2014

[2] he Rong, Gong Shuguang, Li Chun et al. Numerical simulation and experimental study of Fluent based water cooled plate heat sink [J]. fluid machinery, 2010,38 (2)

[3] Xu Guotao. Study on the optimization of the cooling system of the desktop computer [D]. North China Electric Power University (Hebei), 2009 